\title{
PERILAKU KOMUNIKASI PARA PEDAGANG LOKAL DALAM BERINTERAKSI DENGAN TURIS MANCANEGARA DI SEPANJANG PESISIR KUTA DENPASAR BALI
}

\section{Communication Behavior of the Local Beach Seller in Interactin with the Foreign Tourist Along the Coasat of Kuta Beach Denpasar Bali}

\author{
Nettie Nandra Tasunaung, Muh Farid, Tuti Bahfiarti \\ Jurusan Imu Komunikasi, Fakultas Ilmu Sosial dan Ilmu Politik, \\ Universitas Hasanuddin, Makassar (nettienandra@ yahoo.com) \\ Jurusan Imu Komunikasi, Fakultas Ilmu Sosial dan Ilmu Politik, \\ Universitas Hasanuddin, Makassar (tutibahfiarti@yahoo.com) \\ Jurusan Imu Komunikasi, Fakultas Ilmu Sosial dan Ilmu Politik, \\ Universitas Hasanuddin, Makassar (faridemsil@yahoo.com)
}

\begin{abstract}
ABSTRAK
Penelitian ini bertujuan untuk mengetahui (1) perilaku komunikasi dan (2) faktor-faktor penghambat para pedagang lokal dalam berinteraksi dengan turis mancanegara. Penelitian ini dilaksanakan di sepanjang pesisisr pantai Pantai Kuta Denpasar, Bali. Penelitian ini menggunakan pendekatan kualitatif. Data yang diperoleh melalui wawancara, observasi, dan dokumentasi kemudian dianalisis dengan menggunakan analisis data deskriptif. Penentuan informan menggunakan teknik aksidental sampling dengan jumlah informan sebanyak 9 orang. Mereka yang menjadi narasumber merupakan para pedagang lokal dan turis mancanegara. Hasil penelitian ini menunjukkan bahwa meskipun kebudayaan para pedagang lokal dan turis mancanegara berbeda, namun mereka tetap dapat berkomunikasi secara efektif. Interaksi yang berlangsung antara pedagang lokal dan turis mancanegara menggunakan komunikasi verbal, yaitu secara lisan dan tulisan dan komunikasi nonverbal yang berupa simbolsimbol. Para pedagang lokal dalam berinteraksi langsung dengan turis mancanegara mengalami hambatanhambatan dalam masalah bahasa, budaya, dan motivasi. Meskipun pedagang menemui berbagai macam hambatan dalam berinteraksi dengan turis mancanegara, namun para pedagang lokal tetap berusaha mengatasi semua hambatan tersebut agar komunikasi dapat berlangsung dengan efektif.
\end{abstract}

Kata Kunci : Perilaku komunikasi, verbal, non-verbal, pedagang lokal

\section{ABSTRACT}

The aims of study were to (1) observe communication behavior of beach seller in interacting with foreign tourists (2) observe the factors impeding communication of beach seller in interacting with foreign tourists. This research was conducted at Kuta Beach, Denpasar Bali. The study employed a qualitative approach. Data were obtained from interviews, observation, and documentation, and analyzed with descriptive analysis. Informants were 9 beach seller and foreign tourists determined with accidental sampling technique. The results of this study indicated the that although culture among beach seller and foreign tourists were different they still communicate effectively. Interaction between beach seller and foreign tourists used verbal and non-verbal communication with symbols alteration. In their interaction, beach seller perceived language, communication, and culture were barriers to motivation. Despite the obstacles in interacting with foreign tourists, local traders were still trying to cope with all the communication that took place in order to be effective.

Key words : communication behaviour, verbal, non-verbal, beach seller 


\section{PENDAHULUAN}

Bali merupakan sebuah provinsi di Indonesia, Ibu kota provinsi ini adalah Denpasar. Bali terkenal sebagai tujuan pariwisata dengan keunikan berbagai hasil senibudayanya, khususnya bagi para turis mancanegara. Bali juga dikenal dengan julukan Pulau Dewata dan Pulau Seribu Pura. Bali merupakan primadona bagi pariwisata yang terkenal dengan berbagai macam keindahannya yang beranekaragam seperti keindahan alam gunung, pantai dan juga kebudayaan Bali yang identik dengan tarian khas Bali serta berbagai macam kain batik Bali yang memancarkan pesona khas Indonesia. Hal ini yang membuat Bali menjadi tempat yang paling banyak dikunjungi oleh para wisatawan baik wisatawan lokal maupun turismancanegara yang berasal dari berbagai negara di dunia Umumnya mata pencaharian masyarakat Bali di daerah kawasan wisata adalah di bidang kesenian, pertanian, peternakan, industri dan perdagangan. Seluruh daerah di Bali merupakan daerah wisata, maka dari itu kesempatan ini dimanfaatkan oleh para penduduk lokal Bali untuk mencari penghasilan dengan mengandalkan tempat-tempat wisata yang sering kali dikunjungi oleh para turis mancanegara dan wisatawan lokal.

Daerah wisata yang paling banyak dikunjungi oleh turis mancanegara adalah pantai Kuta. Di pantai Kuta banyak sekali ditemui para pedagang lokal yang melakukan aktivitas berjualan di sepanjang pesisir pantai menghampiri para turis mancanegara. Kedatangan turis mancanegara menarik perhatian para pedagang lokal untuk menjual berbagai barang dan jasa seperti aksesoris, kacamata, ice cream, kain Bali, minuman dingin, jasa pijat, jasa tato temporer dan masih banyak lagi. Para pedagang lokal dengan segala keterbatasan yang mereka miliki, tidak menjadi halangan bagi mereka untuk tetap bersemangat mencari nafkah dengan berdagang di sepanjang pesisir pantai kuta. Mereka sangat menyadari bahwa komunikasi sangatlah penting untuk menjalin interaksi satu dengan yang lain. Maka dari itu para pedagang meningkatkan kemampuan berkomunikasi mereka dengan belajar bahasa inggris meski hanya mengetahui angka-angka agar bisa melakukan tawar menawar dengan turismancanegara saat mereka berdagang.

Dalam hal ini fokus penelitian adalah para pedagang lokal dikarenakan dalam berjualan mereka sering bertemu dengan berbagai macam turis mancanegara yang ada di pantai Kuta. Hal ini membuat mereka tentu saja melakukan upaya agar dapat melakukan interaksi dengan turis mancanegara

Dari hasil observasi awal terlihat bahwa para pedagang lokal dapat berinteraksi dengan turis mancanegara dimana ini disebut sebagai komunikasi antar budaya. Menurut Liliweri (2013), komunikasi antarbudaya adalah setiap proes pembagian informasi, gagasan atau perasaan di antara mereka yang berbeda latar belakang budayanya. Proses pembagian informasi itu dilakukan secara lisan dan tertulis, juga melalui bahasa tubuh, gaya atau tampilan pribadi, atau bantuan hal lain di sekitarnya yang memperjelas pesan. Menurut Liliweri (2011), komunikasi dapat diartikan sebagai proses peralihan dan pertukaran informasi oleh manusia melalui adaptasi dari dan dalam sebuah sistem kehidupan manusia dan lingkungannya. Proses pertukaran informasi itu dilakukan melalui simbol-simbol bahasa verbal maupun non-verbal yang dipahami bersama.

Menjadi hal yang menarik karena tidak semua pedagang lokal bisa paham dengan bahasa Inggris dan turis mancanegara juga tidak semua paham bahasa Indonesia. Sehingga untuk mempertegas pesan yang disampaikan maka pedagang lokal menggunakan komunikasi verbal baik lisan maupun tertulis dan komunikasi non-verbal menggunakan simbol-simbol agar terhindar dari kesalahpahaman.

Komunikasi menjadi hal yang paling utama bagi para pedagang lokal agar bisa berkomunikasi dengan para turis mancanegara yang berlatar belakang kebudayaan yang berbeda. Dengan berkomunikasi manusia menyampaikan pesan-pesan, dimana hal itu sebenarnya kita sedang berprilaku. Perilaku disebut sebagai pesan jika telah mengandung dua syarat yaitu: (1) perilaku harus diobservasi oleh seseorang, (2) perilaku harus mengandung makna , Mulyana (2005). Perilaku yang disampaikan secara verbal ataupun non-verbal dapat berfungsi sebagai pesan.

Para pedagang lokal dengan segala keterbatasan yang mereka miliki, tidak menjadi halangan bagi mereka untuk tetap bersemangat mencari nafkah dengan berdagang di sepanjang pesisir pantai kuta dan melakukan interaksi dengan turis mancanegara meskipun memiliki keterbatasan bahasa. Bagaimana kedua individu saling memahami dengan segala 
perbedaan latar belakang budaya. Hal ini yang menarik perhatian penulis untuk mengkaji Perilaku Komunikasi Para Pedagang Lokal dalam Berinteraksi dengan Turis mancanegara di Sepanjang Pesisir Pantai Kuta Denpasar Bali.

\section{BAHAN DAN METODE}

Penelitian ini menggunakan pendekatan kualitatif deskriptif dimana disebutkan oleh Kriyantono (2008), bahwa riset deskriptif bertujuan membuat deskripsi secara sistematis, faktual, dan akurat tentang faktafakta dan sifat-sifat populasi atau objek tertentu. Maka, dalam hal ini peneliti akan melakukan pengamatan secara langsung di lokasi penelitian. Pendekatan kualitatif juga digunakan untuk memahami interaksi sosial serta dengan metode wawancara, diharapkan dapat diketahui bentuk perilaku komunikasi verbal nonverbal dalam kajian komunikasi antarbudaya dan hambatan yang menyebabkan perilaku komunikasi dalam berinteraksi.

\section{LOKASI DAN RANCANGAN PENELITIAN}

Lokasi penelitian di lakukan di sepanjang pesisir pantai Kuta Denpasar Bali. Penelitan dilakukan di Bali karena Bali merupakan tempat pariwisata yang sangat terkenal di Indonesia yang membuat banyak sekali turis mancanegara dan wisatawan lokal datang berwisata. Proses penelitian dilakukan dengan observasi dan wawancara langsung terhadap informan.

\section{SUMBER DATA}

Jenis data yang digunakan terbagi atas dua, yaitu data primer dan data sekunder. Data primer yaitu hasil wawancara langsung terhadap 9 orang informan pedagang lokal dan turis mancanegara yang dipilih dengan sengaja oleh penulis untuk dapat mendukung hasil penelitian. Hasil wawancara tersebut berupa rekaman dengan alat perekam dan data secara tertulis. Data sekunder adalah data yang diperoleh melalui kajian pustaka, dokumen-dokumen, artikel, ataupun hasil penelitian yang relevan dan khususnya data yang berkaitan dengan penelitian komunikasi antar budaya dan perilaku komunikasi.

\section{TEKNIK PENGUMPULAN DATA}

Pengumpulan data dilakukan dengan cara mengamati secara langsung obyek penelitian disertai dengan pencatatan yang diperlukan. Selain itu, dalam hal ini peneliti juga menjalin pertemanan dan secara intens bertemu atau bepergian (mengamati kegiatan dan interaksi) bersama obyek penelitian untuk mengamati proses komunikasi verbal dan nonverbal yang berlangsung dengan turis mancanegara. Kemudian melakukan wawancara dengan menggunakan pedoman pertanyaan terhadap subyek penelitian dan informan yang dianggap dapat memberikan penjelasan mengenai bentuk komunikasi verbal dan non-verbal dengan turis mancanegara dan hambatan-hambatan yang menyebabkan perilaku komunikasi dalam menggunakan komunikasi verbal dan non-verbal saat proses interaksi berlangsung. Bentuk wawancara yang saya lakukan adalah menjaga kerahasiaan informan. Peneliti selalu berperan penting dalam mengedepankan prinsip kesukarelaan informan untuk memberikan data yang diperlukan.

\section{TEKNIK ANALISIS DATA}

Cara analisis data yang digunakan peneliti adalah model interaktif Miles \& Hiberman dalam Moleong (2010) didasarkan empat proses yang berlangsung secara interaktif, yaitu; pengumpulan dan pengambilan data dengan menelaah seluruh data yang tersedia dari berbagai sumber, yaitu wawancara, pengamatan yang sudah ditulis dalam catatan lapangan, dokumentasi pribadi, foto, dan sebagainya.

Kemudian yang kedua mereduksi data merupakan suatu bentuk analisis yang menajamkan, menggolongkan, mengarahkan, membuang yang tidak perlu dan mengorganisasi data dengan cara sedemikian rupa hingga kesimpulan finalnya dapat ditarik dan diverifikasi. Tahap ketiga adalah sajian data yang merupakan suatu rakitan organisasi informasi yang memungkinkan kesimpulan riset dilakukan. Dengan melihat sajian data, peneliti akan lebih memahami berbagai hal yang terjadi dan memungkinkan untuk mengerjakan sesuatu pada analisis ataupun tindakan lain berdasarkan pemahaman tersebut. Semuanya ini disusun guna merakit infromasi secara teratur supaya mudah dimengerti.

Proses yang terakhir yaitu penarikan kesimpulan merupakan pola proses yang dapat dilakukan dari sajian data dan apabila kesimpulan kurang jelas dan kurang memiliki landasan yang kuat maka dapat menambahkan 
kembali pada reduksi data dan sajian data. Kesimpulan yang perlu diverifikasi, yang berupa suatu pengulangan dengan gerak cepat, sebagai pemikiran kedua yang melintas pada peneliti, pada waktu menulis dengan melihat kembali pada field note.

\section{HASIL PENELITIAN}

\section{PERILAKU KOMUNIKASI PARA PEDAGANG LOKAL DALAM BERINTERAKSI DENGAN TURIS MANCANEGARA}

Berdasarkan Tabel 1 dapat dilihat bahwa informan menggunakan komunikasi verbal secara lisan dan tertulis dan komunikasi non-verbal yang berupa simbol-simbol saat berinteraksi dengan turis mancanegara. Komunikasi verbal secara tertulis yaitu ; menggunakan kertas dan pulpen, menggunakan handphone, menggunakan kalkulator dan menulis di pasir menggunakan jari tangan. Adapun simbol-simbol yang termasuk dalam kategori non-verbal yaitu terdiri dari ; gerakan tubuh, gerakan jari-jari, ekspresi wajah (kinesik), posisi mata (okulesik), memeluk, memegang (haptik), hubungan antar ruang dan dan jarak dalam interaksi (proksemik), konsep waktu (kronemik), tampilan yaitu bagaimana cara menampilkan diri, dan pesan-pesan paralinguistik yang merupakan gabungan dari komunikasi verbal dan non-verbal. Gerakan tubuh yang digunakan pedagang lokal seperti menunjukkan barang dagangan, mengangkat jualan dengan kedua tangan untuk diperlihatkan, menggunakan isyarat jari-jari tangan menjumlahkan angka untuk memberitahu harga, dan mengunakan tangan untuk menggambarkan apa yang ingin dikatakan.

Sedangkan ekspresi wajah yang digunakan adalah senyuman, senyuman ini dilakukan untuk menyapa para turis mancanegara. Di mana bentuk senyuman ini dilakukan untuk menunjukkan keramahan. Ekspresi wajah juga dapat menunjukan ekspresi apakah sedang marah, senang atau sedih. Adapun gerakan mata atau posisi mata yang memiliki perbedaan makna, seperti ketika memutarkan bola mata keatas artinya tidak suka atau kesal. tertentu.

Selanjutnya sentuhan yang dimaksud adalah ketika turis mancanegara memeluk atau memegang tangan pedagang lokal untuk mengungkapkan rasa terimakasih. Hal ini dirasakan oleh informan Ni Wayan Sarwini ini merupakan sebuah pengalaman yang jarang ditemui, mengingat di Bali laki-laki tidak boleh menyentuh bahkan memeluk wanita karena dianggap tidak sopan. Proksemik dimana para pedagang mengetahui jarak antarpribadi antar mereka dan turis mancanegara ketika berinteraksi. Kronemik yaitu tentang ketaatan waktu dimana pedagang lokal bergerak dengan lamban sedangkan turis mancanegara yang selalu tepat waktu dan mengerjakan segala sesuatu dengan tepat. Tampilan bagaimana pedagang lokal menampilkan diri dengan gaya biologisnya untuk menarik perhatian dan terlihat profesional. Adapun pesan-pesan paralinguistik yang merupakan gabungan dari perilaku verbal dan non-verbal seperti ketika berbicara terlalu keras dan melakukan gerakan yang menampilkan maksud

Maka dapat disimpulkan bahwa ketika orang-orang dengan kebudayaan yang berbeda berinteraksi pasti akan mempengaruhi perilaku mereka. Dalam hal ini informan pedagang lokal yang berinteraksi dengan turis mancanegara menggunakan komunikasi verbal secara lisan dan tertulis, informan lokal juga menggunakan komunikasi non-verbal yang berupa simbolsimbol untuk memperjelas pesan yang ingin mereka sampaikan. Meskipun sulit bagi para pedagang lokal untuk melakukan komunikasi yang efektif dalam berinteraksi dengan turis mancanegara, para pedagang lokal tetap berusaha menggunakan komunikasi non-verbal yang berupa gerakan badan dan gerakan isyarat agar mereka dapat menyamakan pemaknaan atas apa yang ingin disampaikan.

\section{HAMBATAN PARA PEDAGANG LOKAL DALAM BERINTERAKSI DENGAN TURIS MANCANEGARA}

Berdasarkan Tabel 2 terlihat hambatan para pedagang lokal dalam berinteraksi dengan turis mancanegara terdiri dari 3 jenis hambatan yaitu hambatan bahasa, hambatan budaya dan hambatan motivasi. Pertama hambatan bahasa dikarenakan perbedaan asal negara dengan latarbelakang kebudayaan yang berbeda tentu saja bahasa juga berbeda, hal ini yang mengakibatkan hambatan dalam berinteraksi karena tidak semua pedagang lokal bisa fasih berbahasa inggris. Bentuk hambatan bahasa yaitu berupa, gaya bicara yang terlalu cepat, intonasi, dan tidak bisa fasih berbahasa inggris. 
Kedua hambatan budaya yaitu hambatan yang terjadi dikarenakan latarbelakang kebudayaan berbeda, perbedaan kebudayaan yang dialami pedagang lokal berupa kesadaran akan waktu dimana turis mancanegara melakukan segala sesuatu dengan tepat dan cepat, termasuk dengan gaya bicara mereka yang sangat cepat menyulitkan pedagang untuk dapat memahami apa yang dikatakan turis mancanegara.

Ketiga hambatan motivasi yaitu hambatan yang ditimbulkan akibat tidak ada motivasi dari turis mancanegara sebagai komunikan untuk mendengarkan apa yang disampaikan oleh pedagang lokal ketika pedagang lokal mencoba melakukan interaksi dengan turis mancanegara. Saat pedagang lokal melakukan interaksi dengan turis mancanegara, banyak dari turis mancanegara tidak memberikan respon atau diam dan bersikap cuek tidak perduli, yang membuat komunikasi yang berlangsung antara pedagang lokal dan turis mancanegara tidak efektif.

\section{PEMBAHASAN}

Penelitian ini menunjukkan bahwa ditemukan 4 bentuk perilaku komunikasi verbal secara tertulis dan 7 bentuk komunikasi nonverbal. Komunikasi menjadi hal yang paling utama bagi para pedagang lokal agar bisa berkomunikasi dengan para turis mancanegara yang berlatar belakang kebudayaan yang berbeda. Dengan berkomunikasi manusia menyampaikan pesan-pesan, dimana hal itu sebenarnya kita sedang berprilaku. Menurut Mulyana (2005), Perilaku disebut sebagai pesan jika telah mengandung dua syarat yaitu : (1) perilaku harus diobservasi oleh seseorang, (2) perilaku harus mengandung makna. Perilaku yang disampaikan secara verbal ataupun non-verbal dapat berfungsi sebagai pesan.

Menurut Liliweri (2013), komunikasi antar budaya adalah setiap proses pembagian informasi, gagasan atau perasaan diantara mereka yang berbeda latar belakang budayanya. Proses pembagian informasi itu dilakukan secara lisan dan tertulis, juga melalui bahasa tubuh, gaya atau penampilan pribadi, atau bantuan hal lain disekitarnya yang memperjelas pesan

Mulyana dan Rakhmat (2005), komunikasi antar budaya terjadi bila pengirim pesan anggota dari suatu budaya dan penerima pesannya adalah anggota dari suatu budaya lain. Seperti telah kita lihat, budaya mempengaruhi orang yang berkomunikasi. Budaya bertanggung jawab atas seluruh pembendaharaan perilaku komunikatif dan makna yang di miliki setiap orang. Konsekuensinya, perbendaharaanperbendaharaan yang dimiliki dua orang yang berbeda budaya akan berbeda pula, yang dapat menimbulkan segal macam kesulitan.

Mulyana (2005), simbol atau pesan verbal adalah semua jenis simbol yang menggunakan satu kata atau lebih. Hampir semua rangsangan wicara yang kita sadari termasuk kedalam kategori pesan verbal disengaja, yaitu usaha-usaha yang dilakukan secara sadar untuk berhubungan dengan orang lain secara lisan. Bahasa dapat juga dianggap sebagai suatu sistem kode verbal.

Mulyana (2005), memaparkan bahasa verbal adalah sarana utama untuk menyatakan pikiran, perasaan, dan maksud kita. Bahasa verbal menggunakan kata-kata yang mempresentasikan berbagai aspek realitas individual kita. Komunikasi Nonverbal Secara sederhana adalah semua isyarat yang bukan kata-kata. Samovar dan \& Porter dalam Riswandi (2009), komunikasi nonverbal mencakup semua rangsangan (kecuali rangsangan verbal) dalam suatu setting komunikasi, yang dihasilkan oleh individu dan penggunaan lingkungan oleh individu, yang mempunyai nilai pesan potensial bagi pengirim atau penerima.

Dari hasil penelitian memperlihatkan bahwa selain menggunakan komunikasi verbal secara lisan yaitu dengan menggunakan bahasa inggris, para pedagang lokal juga menggunakan bentuk komunikasi tertulis seperti menggunakan handphone, kalkulator, menulis di pasir dan menggunakan pulpen dan kertas. Pertama para pedagang lokal juga menggunakan bahasa isyarat (kinesik) yang merupakan salah bentuk komunikasi nonverbal untuk memperjelas pesan yang dimaksud. Informan mengaku bahwa dengan menggunakan bahasa isyarat dapat memudahkan para pedagang lokal dalam berinteraksi dengan turis mancanegara. Sementara itu hal yang dialami oleh Ni Wayan Sarwini ketika berinteraksi dengan turis mancanegara Ia menggunakan bahasa isyarat dengan menggunakan jari menunjukkan kain yang Ia jual kepada turis mancanegara yang sedang bersantai di pantai Kuta. 
Kategori komunikasi nonverbal kedua adalah okulesik yaitu bentuk posisi mata, menurut informan Wisnu Irawan ketika berinteraksi dengan turis mancanegara Ia memperhatikan posisi mata atau alis dari turis mancanegara untuk melihat dan mengetahui perilaku apa yang ditunjukan oleh turis apakah mereka memutar bola mata keatas yang bermakna bahwa turis sedang bosan atau kesal. Kategori yang ketiga adalah sentuhan (haptik) yaitu berupa sentuhan dimana turis mancanegara memeluk dan memegang tangan dimana hal ini di alami oleh informan $\mathrm{Bu}$ Mandi. Keempat yaitu proksemik yaitu dimana jarak menentukan kedekatan semakin dekat duduk berarti semakin akrab. Kelima kronemik yaitu tentang waktu dimana menurut informan Made Istawa turis mancanegara selalu cepatcepat dalam segala hal baik berbicara maupun bergerak. Keenam tampilan yaitu bagaimana salah satu Informan I Putu Sumadana bisa tampil dengan profesional saat berjualan. Ke tujuh adalah pesan-pesan paralinguistik yaitu penggunaan verbal dan non-verbal secara bersamaan seperti melakukan suatu gerakan yang memiliki arti makna tertentu sambil berbicara dengan suara keras, hal ini dialami oleh informan Ni Wayan Sarwini. Disebutkan oleh Mulyana (2005), bahwa ketika kita melambaikan tangan, tersenyum, bermuka masam, menganggukkan kepala, atau memberikan suatu isyarat, kita juga sedang berperilaku. Sering perilaku-perilaku ini merupakan pesan-pesan; pesan-pesan itu digunakan untuk mengkomunikasikan sesuatu kepada seseorang.

Dalam bukunya Sihabuddin (2013), mengetengahkan secara ringkas asumsi-asumsi dasar dari teori interaksi simbolik; pertama, manusia mampu menciptakan simbol-simbol dan mempergunakannya; kedua, manusia mempergunakan simbol-simbol tertentu untuk berkomunikasi dengan manusia lain; ketiga, dengan menginterpretasikan simbol-simbol yang diberikan oleh pihak lain seorang individu akan berperilaku tertentu sebagai tanggapan terhadap adanya simbol yang diterima. Dimana hal tersebut sesuai dengan hasil penelitian terhadap perilaku komunikasi para pedagang lokal dalam berinteraksi dengan turis mancanegara.

Namun perlu diketahui bahwa menurut Ruben \& Stewart (2013), untuk menentukan arti dari pesan-pesan tertentu, kita harus lebih jeli memerhatikan pesan-pesan verbal dan non- verbal yang terlibat dalam proses penerimaan informasi. Kita juga harus memerhatikan hubungan, kelompok, organisasi, budaya, dan masyarakat, yang menyediakan konteks di mana pesan verbal dan nonverbal dibentuk, dibagikan, dan ditafsirkan.

Berikut adalah hambatan komunikasi atau yang juga dikenal sebagai communication barrier yakni segala sesuatu yang menjadi penghalang untuk terjadinya komunikasi yang efektif. Seperti yang disebutkan oleh Cangara (2014), bahwa pada dasarnya terdapat 6 rintangan atau gangguan pada komunikasi yaitu; gangguan teknis, gangguan semantik dan psikologis, rintangan fisik, rintangan status, rintangan kerangka berpikir, dan rintangan budaya. Chaney \& Martin (2004), memberikan sembilan jenis hambatan dalam komunikasi antarbudaya. Hambatan-hambatan tersebut yaitu : fisik, budaya, persepsi, motivasi, pengalaman, emosi, bahasa, non-verbal, dan kompetisi.

Dari hasil penelitian ditemukan 3 hambatan yang menjadi hambatan yang menyebabkan perilaku komumikasi verbal dan non-verbal berlangsung secara efektif antara para pedagang lokal dan turis mancanegara yaitu hambatan bahasa, budaya, dan motivasi. Hambatan bahasa terjadi karena adanya perbedaan asal negara yang tentu saja memiliki perbedaan kebudayaan sehingga bahasa menjadi salah satu hambatan utama dalam berinteraksi satu dengan yang lain. Perbedaan utama pada bahasa yaitu logat atau dialek turis mancanegara yang berbeda-beda, setiap negara memiliki ciri khas masing-masing dengan logat atau dialek yang dimiliki. Hal ini membuat para pedagang lokal menemui kendala dalam berinteraksi.

Hal ini tentu dipicu karena adanya perbedaan budaya seperti yang disebutkan oleh Mulyana \& Rakhmat (2010), bahwa budaya bersifat kompleks, abstrak, dan luas. Banyak aspek budaya turut menentukan perilaku komunikatif. Unsur sosio-budaya ini tersebar dan meliputi banyak kegiatan sosial manusia. Di mana unsur sosio-budaya ini merupakan bagian-bagian dari komunikasi antar budaya.

Jenis hambatan yang kedua yaitu hambatan budaya. Hambatan ini disebabkan oleh tata cara bertingkah laku, pola pergaulan sehari-hari, gaya bicara, dan kesadaran akan waktu. Pada hambatan budaya para pedagang lokal mengalami kesulitan dengan gaya bicara turis mancanegara yang 
berbicara sangat cepat dengan logat atau dialek yang berbeda-beda setiap negara yang membuat mereka kesulitan untuk mendengarkan dengan baik dan memahami apa yang di maksud oleh turis mancanegara. Pedagang lokal juga merasa perbedaan tentang waktu dimana pedagang lokal dengan budaya nya yang serba pelan dan hati-hati, sedangkan turis mancanegara menginginkan segala sesuatu dengan cepat yang membuat pedagang lokal sering kebingungan.

Jenis hambatan ketiga yaitu hambatan motivasi. Dimana hambatan ini terjadi karena di pengaruhi oleh tingkat motivasi pendengar yang dalam hal ini adalah turis mancanegara. Ketika para pedagang lokal melakukan interaksi dengan turis mancanegara ada beberapa turis yang merespon baik ada juga yang bersikap tidak perduli, biasanya ketika percakapan berlangsung ada turis mancanegara yang hanya diam dan tersenyum sambil mengangkat tangan yang bermakna tidak. Ada yang sambil membaca buku menjawab dengan singkat setiap pertanyaan yang di ungkapkan ole pedagang lokal, namun ada juga yang dengan baik menjawab tidak terimakasih. Inilah yang seringkali menjadi penyebab komunikasi yang tidak efektif.

\section{KESIMPULAN DAN SARAN}

Berdasarkan hasil analisa dan hasil wawancara terhadap informan yaitu pedagang lokal ditemukan bahwa para pedagang lokal melakukan pengamatan dan menggunakan segala bentuk komunikasi verbal dan komunikasi non-verbal untuk membantu mereka dalam menyampaikan pesan yang di maksud agar bisa terjalin komunikasi yang efektif saat interaksi berlangsung. Meskipun sering menemukan hambatan-hambatan dalam berinteraksi karena pemahaman yang berbeda yang dipengaruhi oleh budaya mereka yang berbeda juga. Namun dengan sikap yang baik para pedagang lokal menerima perbedaan budaya turis mancanegara maka pedagang lokal dapat menciptakan komunikasi yang efektif dengan turis mancanegara. Sebagai saran peneliti bahwa sebaiknya para pedagang lokal dan turis mancanegara belajar untuk memahami lebih jauh tentang budaya diluar dari kebudayaan sendiri agar dapat memahami perbedaan budaya sehingga dapat menciptakan komunikasi yang baik dan efektif.

\section{DAFTAR PUSTAKA}

Cangara. (2014). Pengantar Ilmu Komunikasi. Jakarta: PT. Raja Grafindo Persada

Chaney \& Martin. (2004). Intercultural business communication. New Jersey: Pearson

Education. Inc.

Kriyantono. (2008). Teknik Praktis Riset Komunikasi. Jakarta: Prenada Media Group

Liliweri. (2013). Dasar-Dasar Komunikasi Antarbudaya. Yogyakarta: Pustaka Pelajar

Liliweri. (2011). Gatra-Gatra Komunikasi Antarbudaya. Yogyakarta: Pustaka Pelajar

Moleong. (2010). Metode Penelitian Kualitatif. Bandung: Remaja Rosdaarya

Mulyana. (2005). Ilmu Komunikasi: Suatu Pengantar. Bandung: Remaja Rosdakarya

Mulyana \& Rakhmat. (2010). Komunikasi Antarbudaya: Panduan

Berkomunikasi dengan OrangOrang Berbeda Budaya. Bandung: Remaja Rosdakarya

Riswandi. (2009). Ilmu Komunikasi. Yogyakarta : Graha ilmu.

Ruben \& Stewart. (2013). Komunikasi dan Perilaku Manusia. Jakarta: PT. Raja Grafindo Persada

Sihabudin. (2013). Komunikasi Antarbudaya Satu Perpsektif Multidimensi. Jakarta: Bumi Aksara 


\section{LAMPIRAN}

Tabel 1, Perilaku Komunikasi Para Pedagang Lokal Dalam Berinteraksi Dengan Turis Mancanegara

No Nama

\section{Perilaku Komunikasi}

Verbal

Non-verbal

\begin{tabular}{|c|c|c|c|}
\hline 1 & $\begin{array}{c}\text { I Putu } \\
\text { Sumadana }\end{array}$ & $\begin{array}{ll}\text { Bahasa } & \text { (lisan), dapat } \\
\text { berbahasa } & \text { Inggris dengan } \\
\text { baik } & \\
\text { Tulisan, menggunakan } \\
\text { kertas dan pulpen }\end{array}$ & $\begin{array}{l}\text { Gesture tangan (menunjukkan gambar } \\
\text { pada buku) } \\
\text { Kinesik (tampilan wajah, menunjukkan } \\
\text { ekpresi senang, sedih, tersenyum) } \\
\text { Okulesik (gerakan mata, memutar bola } \\
\text { mata keatas) }\end{array}$ \\
\hline 2 & $\begin{array}{c}\text { Ni Wayan } \\
\text { Sarwini }\end{array}$ & $\begin{array}{l}\text { Bahasa (lisan), } \\
\text { menggunakan bahasa } \\
\text { Inggris sebanyak kosa kata } \\
\text { yang dihafalkan } \\
\text { Tulisan, menulis di pasir }\end{array}$ & $\begin{array}{l}\text { Body language (menggunakan jari } \\
\text { telunjuk menunjukkan kain, atau } \\
\text { memegang kain dan menunjukkan pada } \\
\text { turismancanegara) } \\
\text { Kinesik (tampilan wajah menunjukan } \\
\text { ekspresi senang, sedih,marah) } \\
\text { Pesan-pesan paralinguistik }\end{array}$ \\
\hline 3 & $\begin{array}{l}\text { Wisnu } \\
\text { Irawan }\end{array}$ & $\begin{array}{l}\text { Bahasa (lisan), fasih } \\
\text { menggunakan bahasa } \\
\text { Inggris } \\
\text { Tulisan, handphone }\end{array}$ & $\begin{array}{l}\text { Menggerakan tangan menggunakan jari- } \\
\text { jari } \\
\text { Ekspresi Wajah (Senang, sedih, marah) } \\
\text { Okulesik (bentuk alis dan posisi mata) } \\
\text { Pesan-pesan paralinguistik }\end{array}$ \\
\hline 4 & $\begin{array}{l}\text { Made } \\
\text { Istawa }\end{array}$ & $\begin{array}{l}\text { Bahasa (lisan), menguasai } 3 \\
\text { bahasa, fasih berbahasa } \\
\text { Inggris } \\
\text { Tulisan, ---- }\end{array}$ & $\begin{array}{l}\text { Hand Gestures (menggunakan jari tangan } \\
\text { untuk memberitahu harga) }\end{array}$ \\
\hline 5 & $\begin{array}{l}\text { Bu Mandi } \\
\text { Nyoman }\end{array}$ & $\begin{array}{l}\text { Bahasa (lisan), } \\
\text { menggunakan bahasa } \\
\text { Inggris, cukup fasih. } \\
\text { Tulisan, kalkulator }\end{array}$ & $\begin{array}{l}\text { Body Language (menggerakan jari-jari } \\
\text { untuk memberitahu harga) } \\
\text { Ekspresi wajah (senang, sedih, marah) }\end{array}$ \\
\hline
\end{tabular}


Tabel 2. Hambatan Komunikasi Para Pedagang Lokal Dalam Beinteraksi Dengan Turis Mancanegara

\section{No Nama Hambatan Komunikasi Para Pedagang Lokal Dalam Berinterasi Dengan Turis Mancanegara}

\section{Bahasa $\quad$ Budaya $\quad$ Motivasi}

\begin{tabular}{|c|c|c|c|c|}
\hline 1 & $\begin{array}{l}\text { I Putu } \\
\text { Sumadara }\end{array}$ & $\begin{array}{l}\text { Penggunaan Logat } \\
\text { lokal (negara) } \\
\text { Intonasi } \\
\text { Artikulasi tidak } \\
\text { jela`s }\end{array}$ & $\begin{array}{l}\text { Kebanyakan turismancanegara } \\
\text { menyukai seni tatoo terutama } \\
\text { turis Australia }\end{array}$ & ------------- \\
\hline 2 & $\begin{array}{l}\text { Ni Wayan } \\
\text { Sarwini }\end{array}$ & $\begin{array}{l}\text { Logat atau dialek } \\
\text { negara } \\
\text { Artikulasi tidak } \\
\text { jelas } \\
\text { Kurang jelas } \\
\text { mendengarkan } \\
\text { Gaya bicara }\end{array}$ & $\begin{array}{l}\text { Turis mancanegara yang } \\
\text { memeluk ketika mengucapkan } \\
\text { terimakasih }\end{array}$ & $\begin{array}{l}\text { Tingkat } \\
\text { motivasi } \\
\text { pendengar }\end{array}$ \\
\hline 3 & $\begin{array}{l}\text { Wisnu } \\
\text { Irawan }\end{array}$ & $\begin{array}{l}\text { Logat atau dialek } \\
\text { negara } \\
\text { Artikulasi tidak } \\
\text { jelas } \\
\text { Intonasi } \\
\text { Gaya bicara }\end{array}$ & $\begin{array}{l}\text { Waktu, turismancanegara yang } \\
\text { segala sesuatu cepat-cepat }\end{array}$ & ------------- \\
\hline 4 & $\begin{array}{l}\text { Made } \\
\text { Istawa }\end{array}$ & $\begin{array}{l}\text { Berbicara terlalu } \\
\text { cepat } \\
\text { Logat atau dialek } \\
\text { Artikulasi tidak } \\
\text { jelas }\end{array}$ & $\begin{array}{l}\text { Turismancanegara } \\
\text { Australia ramah dan suara } \\
\text { tertawa yang keras }\end{array}$ & ------------- \\
\hline 5 & $\begin{array}{l}\text { Mandi } \\
\text { Nyoman }\end{array}$ & $\begin{array}{l}\text { Bahasa } \\
\text { Bicara terlalu cepat } \\
\text { Gaya Bicara }\end{array}$ & $\begin{array}{l}\text { Meggunakan kursi balita kepada } \\
\text { balita yang telah besar } \\
\text { Bayi berusia hari atau awal bulan } \\
\text { dibawa keluar malam hari } \\
\text { Memegang tangan }\end{array}$ & $\begin{array}{l}\text { Tingkat } \\
\text { motivasi } \\
\text { pendengar }\end{array}$ \\
\hline
\end{tabular}

